\title{
Fatal fistula between the trachea and the brachiocephalic artery: Late complication of a second-generation, self-expanding metallic tracheal stent
}

\author{
Eero I. T. Sihvo, MD, PhD, ${ }^{\text {a }}$ Thanos Sioris, MD, PhD, ${ }^{\text {a }}$ Olli Tynninen, MD, PhD, ${ }^{\mathrm{b}}$ and Jarmo A. Salo, MD, PhD,
}

Helsinki, Finland

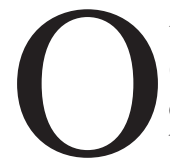

ver the past decade, the self-expanding metallic stent (SEMS) has been considered a safe and effective modality for treatment of inoperable malignant and selected benign airway diseases. Cases of life-threatening or massive hemoptysis have, however, occurred after placement of firstgeneration tracheal SEMSs. We report a case in which a secondgeneration tracheal SEMS caused ulcer formation and a fistula between the trachea and the brachiocephalic artery 40 months after insertion and discuss the cause, pathogenesis, and clinical features of the massive airway bleeding.

\section{Clinical Summary}

A 70-year-old man was treated with local resection and intratracheal brachytherapy because of tracheal adenoid cystic carcinoma. When first seen 16 months later at the Helsinki University Central Hospital, the patient had stridor and dyspnea because of tumor recurrence. Flexible bronchoscopy revealed a 5-cm-long inoperable tumor covered by a 60-mm-long SEMS with a diameter of 18 mm (Ultraflex; Boston Scientific, Galway, Ireland). During the following year, local tumor growth was treated twice with the Nd:YAG laser. Twenty months after SEMS insertion, the broken proximal portion of the first stent was covered with a second 40-mm-long, 20-mm-diameter Ultraflex. During the following year, the patient experienced episodes of increasing breathlessness and underwent 4 tracheal dilations for progressive airway stenosis. Then 37 months after the first SEMS was placed, a third covered Ultraflex was applied over the broken area of the previous stent and over a new more proximal stenosis in the trachea. Three months later, our patient called and complained about hemoptysis. Massive hemoptysis was the cause of death en route to the hospital.

Autopsy revealed a hematoma underneath the proximal area of the tracheal stents and a fistula between the trachea and the brachiocephalic artery (Figure 1). Airways were filled with blood.

From the Division of General Thoracic and Esophageal Surgery, Department of Cardiothoracic Surgery, ${ }^{a}$ and the Central Laboratory of Pathology, ${ }^{\text {b }}$ Helsinki University Central Hospital, Helsinki, Finland.

Received for publication Jan 11, 2006; accepted for publication Feb 6, 2006.

Address for reprints: Jarmo A. Salo, MD, PhD, Division of General Thoracic and Esophageal Surgery, Department of Cardiothoracic Surgery, Helsinki University Central Hospital, PO Box 340, Haartmaninkatu 4, FIN-00029 HUS, Helsinki, Finland (E-mail: jarmo.salo@hus.fi).

J Thorac Cardiovasc Surg 2006;131:1415-6

$0022-5223 / \$ 32.00$

Copyright () 2006 by The American Association for Thoracic Surgery

doi:10.1016/j.jtcvs.2006.02.004
Histology revealed wide areas of tumor growth underneath the tracheal epithelium. In the fistular area an ulcer had penetrated the tracheal rings, causing the fatal fistula.

\section{Discussion}

The literature provided us no case in which a tracheal secondgeneration SEMS has caused a fistula between the trachea and the brachiocephalic artery. Once, in a patient with a permanent tracheostomy after laryngectomy and tracheal stenosis, a firstgeneration Gianturco stent caused such a fistula. ${ }^{1}$ Long-term treatment of a tracheal stenosis with a silicon prosthesis has resulted in a fistula between the trachea and the brachiocephalic artery as well. ${ }^{2}$

Of those 13 reported patients in whom SEMSs have resulted in massive hemoptysis, 3 second-generation stents (2 Wallstents and 1 Ultraflex) were inserted in the left main bronchus, ${ }^{3}$ and 10 first-generation either Gianturco $(n=6)$ or Palmaz $(n=4)$ stents were inserted in the left main bronchus $(n=6)$ or the trachea $(\mathrm{n}=4)^{1,4-10}$ Indications for SEMS placement was a benign disease in 11: malacia in 4, external compression by the dissected aorta or aortic anomaly in 2, stenosis after tracheostomy in 2, and 1 each of postoperative bronchial stenosis, congenital tracheal stenosis, and bronchial dehiscence after single-lung transplantation. ${ }^{1,3,4,6-10}$ In 2 patients either bronchial or esophageal cancer has reoccurred. ${ }^{5}$ Bleeding after stent placement has occurred in 7 cases early in merely days or weeks. As a late complication, 13 months to 7 years, massive hemoptysis occurred 6 times. ${ }^{4,8-10}$ The mechanism of bleeding has varied. In 2 children and 1 adult, a stent of the left main bronchus has eroded either into the descending aorta or a bronchial artery, leading to mycotic aneurysm and life-threatening hemorrhage. ${ }^{4}$ In 5 cases a bronchial stent caused a direct communication between the bronchus and the descending aorta or aortic arch. ${ }^{3,5,7,10}$ In 2 infants a tracheal stent led to a fistula between the trachea and the pulmonary artery or the left inferior thyroid artery. ${ }^{6,8}$ In many cases the cause of massive hemoptysis has not, however, been identified at autopsy. ${ }^{11}$

Our patient survived more than 40 months after detection of cancer recurrence in the trachea and the application of a tracheal SEMS. Before death, he underwent 8 more therapeutic bronchoscopies including dilation, laser therapy, and 2 additional stents. Reports of long-term outcomes of patients with SEMSs are scarce, and many times, good results require repeated procedures that cause trauma to the airways; this, together with the mechanical stress caused by a stent, can lead to a full-thickness ulcer and a fistula. Our experience with tracheal or bronchial SEMSs includes more than 100 patients. Of them, only 17 patients have survived with an SEMS for more than 3 years; one had fatal hemoptysis, for a prevalence of $6 \%$. Before 

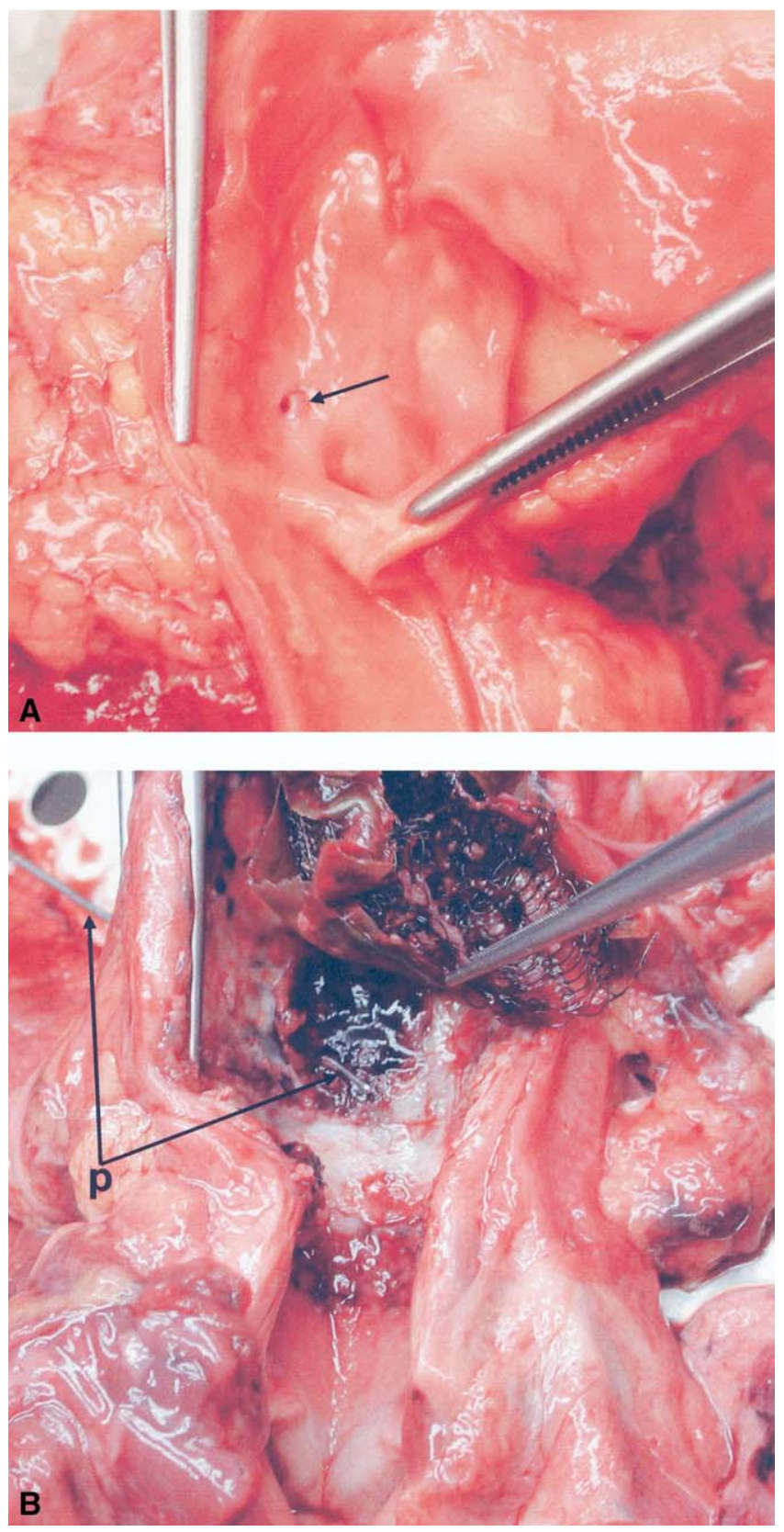

Figure 1. Autopsy photos of longitudinal opening of the brachiocephalic and right carotid arteries (A) and of the trachea (B). A, Arterial ostium of the fistula just proximal to bifurcation of the brachiocephalic artery (arrow). B, The probe (p) inserted into the fistula reveals communication between the brachiocephalic artery and the trachea and a hematoma beneath the upper portion of the tracheal Ultraflex. we gain more knowledge of long-term results, these secondgeneration stents must be used with caution in patients expected to live for years.

\section{References}

1. Grundmann T, Brachtel E, Kehrl W. Fistula between the trachea and innominate artery - a rare complication following tracheostenosis treatment with silastic tubes. Laryngorhinootologie. 1999;78:91-6.

2. Katayama Y, Suzuki H, Mizutani T. Aorto-bronchial fistula after implantation of a self-expanding stent in a patient with aortic dissection. Jpn J Thorac Cardiovasc Surg. 2000;48:73-5.

3. Wadsworth SJ, Juniper MC, Benson MK, Gleeson FV. Fatal complication of an expandable metallic bronchial stent. $\mathrm{Br} J$ Radiol. 1999; 72:706-8.

4. Onishi H, Kuriyama K, Komiyama T, et al. A case of aorto-bronchial fistula after insertion of left main bronchial self-expanding metallic stent in a patient with recurrent esophageal cancer. Cardiovasc Intervent Radiol. 2004;27:288-90.

5. Miyamoto T, Ishida R, Noma M, Chikada M, Sekiguchi A. Successful surgical management of a tracheopulmonary artery fistula caused by an intratracheal expandable metal stent. Jpn J Thorac Cardiovasc Surg. 2001;49:632-4.

6. Cook $\mathrm{CH}$, Bhattacharyya N, King DR. Aortobronchial fistula after expandable metal stent insertion for pediatric bronchomalacia. $\mathrm{J} \mathrm{Pe}$ diatr Surg. 1998;33:1306-8.

7. Stotz WH, Berkowitz ID, Hoehner JR, Tunkel DE. Fatal complication from a balloon-expandable tracheal stent in a child: a case report. Pediatr Crit Care Med. 2003;4:115-7.

8. Alfaro J, Varela G, De-Miguel E, Martin de Nicolas JL. Successful management of a tracheoinnominate fistula following placement of a wire self-expandable tracheal Gianturco stent. Eur J Cardiothorac Surg. 1993;7:615-6.

9. Maynar M, Lopez L, Gorriz E, et al. Massive brachiocephalic artery bleeding due to a Gianturco tracheal stent. J Vasc Intervent Radiol. 1993:4:289-91.

10. Nouraei SM, Pillay T, Hilton CJ. Emergency management aortobronchial fistula after implantation of a self-expanding bronchial stent. Eur J Cardiothorac Surg. 2001;20:642-4.

11. Wood DE, Liu YH, Vallieres E, Karmy-Jones R, Mulligan MS Airway stenting for malignant and benign tracheobronchial stenosis. Ann Thorac Surg. 2003;76:167-74. 